\title{
Suscetibilidade Antimicrobiana e Fatores de Virulência de Staphylococcus em Fômites do Hospital Universitário Sul Fluminense
}

\section{Antimicrobial Susceptibility and Virulence Factors of Staphylococcus in Fomites of Sul Fluminense University Hospital}

\author{
CAROLINE DA COSTANOEL ${ }^{1}$ \\ FRANCINE MOTTA SILVÉRIO ${ }^{1}$ \\ NEILA LILYANE DA SILVA GOMES FRANCISCO² \\ NÁDIA ROSSI DE ALMEIDA ${ }^{3}$ \\ LIDIANE DE CASTRO SOARES ${ }^{3}$
}

\section{RESUMO}

Objetivo: Caracterizar os fatores de virulência e o perfil de suscetibilidade antimicrobiana de isolados de Staphylococcus spp. provenientes de amostras de jaleco e estetoscópio dos profissionais de saúde, e das maçanetas das portas da enfermaria e Unidade de Terapia Intensiva do Hospital Universitário Sul Fluminense. Material e Métodos: As amostras de estetoscópio, maçaneta e jaleco, foram coletadas com"swab" estéril umedecido em solução salina e foram colocados em caldo Infusão de Cérebro e Coração Bovino (BHI) e incubados por $24-48 \mathrm{~h}$ a $37^{\circ} \mathrm{C}$ para o crescimento. Foram feitas as identificações necessárias para caracterização dos fatores de virulência e o perfil de suscetibilidade antimicrobiana de isolados de Staphylococcus spp. no laboratório de Microbiologia da Universidade Severino Sombra. Resultados: Foi obtido um total de 59 Staphylococcus spp, identificados como Staphylococcus aureus $(n=6)$ e Staphylococcus coagulase negativos $(n=53)$. Do grupo coagulase-negativo foram identificados 34 isolaods de Staphylococcus epidermidis e 19 de Staphylococcus saprophyticus. Em relação aos fatores de virulência, $76,3 \%$ isolados foram produtores de "slime". A hemólise foi detectada em $50,9 \%$ dos isolados, destes $35,6 \%$ apresentaram hemólise total e $15,3 \%$ a hemólise parcial. O sinergismo hemolítico foi positivo em $59,3 \%$ dos isolados sendo que destes, 13 não apresentaram hemolisinas. De acordo com o perfil de suscetibilidade, $96,6 \%$ foram resistentes à penicilina. A gentamicina foi o antibiótico que apresentou menor percentual de resistência (15,3\%). Conclusão: Os jalecos, estetoscópios e maçanetas das portas, podem ser considerados como um veículo potencial para transmissão de microorganismo dentro do ambiente hospitalar.

\section{DESCRITORES}

Fatores de Virulência. Antibiograma. Staphylococcus.

\begin{abstract}
Objective: To characterize the virulence factors and antimicrobial susceptibility profile of Staphylococcus spp. from samples of lab coat and stethoscope of health professionals, and from the handles of the doors of the ward and intensive care unit of Sul Fluminense University Hospital. Materials and Methods: The samples from stethoscopes, handles and coats were collected using moistened sterile swabs soaked in saline. Then the swabs were placed in Brain Heart Infusion (BHI) broth and incubated for 24 to $48 \mathrm{~h}$ at $37^{\circ} \mathrm{C}$ for growth. Then we further characterized the virulence factors and antimicrobial susceptibility of Staphylococcus spp. in the Microbiology Laboratory of Severino Sombra University. Results: A total of 59 isolates of Staphylococcus spp. were recovered, of which six were Staphylococcus aureus and 53 were coagulasenegative Staphylococcus. Among the coagulase-negative isolates, 34 were Staphylococcus epidermidis and 19 Staphylococcus saprophyticus. As for virulence factors, $76.3 \%$ of the isolates were slime-producers. Hemolysis was detected in $50.9 \%$ of the isolates, of which $35.6 \%$ showed total hemolysis and $15.3 \%$ partial hemolysis. The hemolytic synergism was positive in $59.3 \%$ of the isolates and of these, 13 showed no hemolysin. According to the susceptibility profile, $96.6 \%$ were resistant to penicillin. Gentamicin was an antibiotic that showed the lowest percentage of resistance (15.3\%). Conclusion: Lab coats, stethoscopes and door handles can be considered as a potential vehicle for the transmission of microorganisms within the hospital environment.
\end{abstract}

DESCRIPTORS

Virulence Factors. Antibiogram. Staphylococcus.

Aluna pela Universidade Severino Sombra (USS), Vassouras/RJ - Brasil.

2 Mestranda em Higiene Veterinária e Processamento Tecnológico de Produtos de Origem Animal pela UFF. Analista de Laboratório Pleno (microbiologia) na Vigor S/A, Barra do Piraí/RJ - Brasil.

3 Professor Adjunto I Universidade Severino Sombra (USS), Vassouras/RJ - Brasil. 
$\mathrm{O}$ ambiente hospitalar é um local repleto de micro-organismos, que podem ser transmitidos de uma pessoa para outra ${ }^{1}$

A Infecção Hospitalar $(\mathrm{IH})$ é definida como aquela adquirida após a internação do paciente e que se manifesta 72 horas após a internação ou 48 horas após a alta e quando puder ser relacionada com a internação ou procedimentos hospitalares ${ }^{1,2}$. A prevalência dessas infecções é crescente, levando ao aumento da mortalidade e gastos intrahospitalares ${ }^{3,4}$. Qualquer paciente está sujeito a contrair uma $\mathrm{IH}$, principalmente os que estão em Unidades de Terapia Intensiva (UTI), que estão em um longo período de internação e passaram por procedimentos cirúrgicos ${ }^{5}$.

Essas infecções podem ser disseminadas pela equipe médica, como também pelos equipamentos utilizados por eles para atender os pacientes. Essa transmissão se dá principalmente pelo contato direto, onde os profissionais tocam pacientes que estão infectados e não higienizam suas mãos e não fazem a assepsia de seus fômites para examinar outro enfermo ${ }^{5}$. Sabe-se que objetos que parecem ser inofensivos como jaleco, estetoscópio e maçanetas, podem ser lugares propícios para a proliferação de micro-organismos ${ }^{6}$.

O Staphylococcus spp. é um microrganismo que faz parte da microbiota normal da pele e mucosa dos seres humanos ${ }^{7}$. É a bactéria mais importante e relacionada com as infecções nosocomiais, por apresentar uma grande capacidade de adquirir resistência a antimicrobianos, principalmente à classe dos â-lactâmicos, além de produzir uma variedade de fatores de virulência, como biofilmes e hemolisinas, que contribuem na invasão das defesas fagocíticas do hospedeiro, facilitando a sua aderência às células epiteliais e a colonização dos tecidos e persistência extracelular ${ }^{8}$.

As infecções por Staphylococcus aureus resistente à meticilina (MRSA) foram consideradas um problema predominantemente hospitalar até a década de 1980, quando foram registrados os primeiros casos por cepas de origem comunitária ou Staphylococcus aureus resistente à meticilina adquirido em comunidade (CA-MRSA). Desde então, cepas de MRSA exibindo características genéticas e fenotípicas diferentes das apresentadas pelas cepas hospitalares, Staphylococcus aureus resistente à meticilina adquirido em hospitais (HAMRSA) passaram a ser identificadas na comunidade causando infecções em pessoas saudáveis, não expostas aos habituais fatores de risco, resultando na mudança da epidemiologia destes microorganismos ${ }^{8}$. Esta resistência limita as opções terapêuticas e prolonga o tempo de tratamento dessas infecções ${ }^{2,9,10}$.

Diante desta situação, grande tem sido o interesse em identificar os principais focos de $\mathrm{IH}$, para então diminuir a resistência antimicrobiana e seus gastos, além das mortes causadas por microrganismos presentes no ambiente hospitalar. O objetivo do trabalho foi isolar Staphylococcus spp. obtidos a partir de amostras de estetoscópios e jalecos de toda a equipe médica, bem como de maçanetas da enfermaria e da UTI do Hospital Universitário Sul Fluminense (HUSF) e avaliar seu perfil de suscetibilidade antimicrobiana e seus fatores de virulência.

\section{MATERIAIS E MÉTODOS}

Foram coletadas amostras através de uma leve fricção de um "swab" estéril umedecido em solução salina, de objetos inanimados como jaleco(parte de bolsos, mangas e punhos), estetoscópio(parte do diafragma) e maçanetas da UTI adulta e infantil, e das enfermarias do Hospital Universitário Sul Fluminense (HUSF) (Tabela 1).

As amostras foram coletadas de profissionais da área da saúde como médicos, acadêmicos e enfermeiros que estavam disponíveis no momento

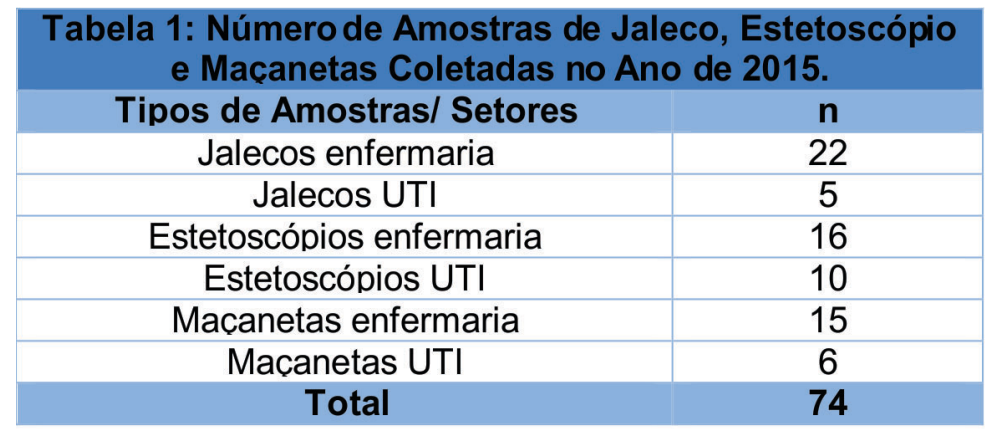


da coleta. As coletas foram feitas em duas etapas, sendo a primeira coleta realizada em maio de 2015 e a segunda em agosto de 2015.

Após a coleta, as amostras foram transportadas imediatamente, sob condições adequadas de refrigeração para o Laboratório de Microbiologia da Universidade Severino Sombra (USS). Posteriormente, os "swabs" com as amostras foram colocados em caldo BHI (Kasvi®) e incubados por $24-48$ horas a $37^{\circ} \mathrm{C}$ para crescimento.

Todas as amostras coletadas foram inoculadas em meios enriquecidos e seletivos e diferenciais. No isolamento primário foi utilizado ágar sangue de carneiro $5 \%$ (NewProv $\AA$ ). As colônias isoladas foram submetidas ao método de Gram, teste da catalase e hidróxido de potássio $(\mathrm{KOH})$ a $3 \%$. De acordo com as características morfotintoriais e de crescimento, os isolados foram inoculados em ágar Manitol Vermelho de Fenol (MVF) (Himidea $($ ) para melhor identificação ${ }^{11}$.

As colônias isoladas foram semeadas em ágar MVF, meio seletivo para Staphylococcus spp. para observação dos aspectos fenotípicos característicos do gênero, como a fermentação ou não do manitol. A identificação foi efetuada por meio do procedimento padrão: prova da coagulase, sensibilidade à bacitracina e fermentação de açúcares ${ }^{11}$.

Para a diferenciação das espécies de Staphylococcus Coagulase Negativa (SCN) em Staphylococcus epidermidis (S. epidermidis) e Staphylococcus saprophyticus (S. saprophyticus) foi feita o teste da novabiocina. A amostra foi semeada em placa de Petri contendo o meio Müeller-Hinton (NewProv $($ ), em seguida foi colocado o disco de antibiótico de novabiocina $5 \mu \mathrm{g} / \mathrm{mL}$ e verificando o crescimento do halo. A formação de halo d" $16 \mathrm{~mm}$, identifica $S$. saprophyticus, pois estes são resistentes a novabiocina. Os que apresentam halo e" 17 são sensíveis e caracterizando $S$. epidermidis ${ }^{12}$.

Os Stapylococcus spp. foram submetidos aos testes de suscetibilidade segundo os padrões do CLSI ${ }^{12}$.

Os isolados de estafilococos foram suspensos em caldo $\mathrm{BHI}$, incubados durante 24 horas a uma temperatura de $37^{\circ} \mathrm{C}$ e diluídos na concentração do tubo 0,5 da escala de Mc Farland, equivalente a $1,5 \times 10^{6}$ células $/ \mathrm{mL}$. Uma suspensão bacteriana $(0,1 \mathrm{~mL})$ foi distribuída por toda a superfície das placas contendo ágar Müeller Hinton com o auxílio de um "swab" estéril. Os discos foram depositados sobre a superfície do meio de cultura, já contendo o inóculo. Após incubação por 24 horas a $37^{\circ} \mathrm{C}$, o perfil de suscetibilidade aos antimicrobianos de eleição foi avaliado através da medição do tamanho, em milímetros, da área de inibição dos antibióticos ${ }^{13}$. Foram utilizados os seguintes antibióticos: A eficácia comparativa da cefalotina $(30 \mu \mathrm{g})$, cefoxitina $(30 \mu \mathrm{g})$, ceftriaxona $(30 \mu \mathrm{g})$, ciprofloxacina $(5 \mu \mathrm{g})$, clindamicina $(2 \mu \mathrm{g})$, enrofloxacina $(10 \mu \mathrm{g})$, gentamicina $(10 \mu \mathrm{g})$, imipenem $(10 \mu \mathrm{g})$, linezolida $(30 \mu \mathrm{g})$, norfloxacina $(10 \mu \mathrm{g})$, penicilina (10UI), oxacilina $(1 \mu \mathrm{g})$, tetraciclina $(30 \mu \mathrm{g})$, foram analisados para todos os isolados.

Para a detecção de produção de â-lactamase foi utilizado o teste da borda. Foi colocado um disco de penicilina de $10 \mu \mathrm{g}$ em ágar Müeller-Hinton, e verificado o tipo de borda formada no halo de inibição. A deteç̧ão de borda definida indica âlactamase negativa e penicilina resistente, e a presença da borda difusa indica â-lactamase positiva e penicilina resistente ${ }^{12}$.

Para a detecção do fenótipo $\mathrm{MLS}_{\mathrm{B}}$ os isolados foram submetidos ao teste de duplo disco para caracterização dos fenótipos de resistência a macrolídeos, sendo o disco de eritromicina (15ì g ) aplicado a $20 \mathrm{~mm}$ de distância ao de clindamicina (2ìg). O fenótipo $\mathrm{MLS}_{B}$ é caracterizado como constitutivo $\left(\mathrm{CMLS}_{\mathrm{B}}\right)$ quando isolados resistentes apresentarem halos de inibição reduzidos ao redor dos discos ou indutivo ( iMLS $_{B}$ ) quando halo de inibição ao redor do disco de clindamicina sofre uma constrição de diâmetro próximo ao disco de eritromicina. Já o fenótipo M é caracterizado pela resistência apenas a eritromicina ${ }^{14}$.

Foram realizados três testes de fatores de virulência diferentes, sendo o primeiro a produção de "slime" em microplacas. Esse teste foi baseado na metodologia de Christensen e colaboradores, onde os isolados foram semeados em ágar sangue por 24 horas a $37^{\circ} \mathrm{C}$ e as colônias foram inoculadas em microplacas de 96 poços contendo caldo tripticase soja (Himidea $\left.{ }^{\circledR}\right)$ a $0,24 \%$ de glicose, e novamente incubadas por 24 horas. Após crescimento bacteriano o caldo foi descartado vertendo-se a microplaca. Os poços foram lavados com água destilada e corados com fucsina por 30 minutos em temperatura ambiente. A produção de "slime" é observada como uma película aderida ao fundo da placa ${ }^{15}$. Os resultados foram avaliados através de leitura visual segundo a escala: ausente $(-)$, fraco $(+)$, moderado $(++)$ e forte $(+++)$.

$O$ segundo teste foi a produção de hemolisinas. Os isolados foram semeados através 
de estrias radiais em ágar sangue para avaliação da produção de halos de hemólise total e parcial após 24 horas a $37^{\circ} \mathrm{C}$. Isolados de Staphylococcus produtores de hemólise parcial foram denominados á-hemolíticos enquanto que os produtores de hemólise total são denominados â-hemolíticos ${ }^{11}$.

Por fim, foi avaliado o Sinergismo Hemolítico (SHA) através do inóculo de $S$. aureus produtor de â-hemolisina em ágar sangue e os isolados foram semeados perpendicularmente a este. Uma zona de hemólise total dentro da zona parcial de âhemolisina foi considerada como SHA positivo ${ }^{16}$.

A cepa padrão de S. aureus (ATCC 25923) será utilizada como controle dos três testes.

\section{RESULTADOS}

Do total de 74 amostras coletadas, após a identificação, foi obtido um total de 59 isolados de Staphylococcus spp., sendo 10,2\% (6/59) de S. aureus, $57,6 \%(34 / 59)$ de $S$. epidermidis e $32,2 \%$ (19/59) de S. saprophyticus (Tabela 2).

Após identificação bacteriana, os isolados foram avaliados quanto ao perfil de suscetibilidade aos antimicrobianos (tabela 3). Dos 59 isolados avaliados, $96,6 \%$ foi resistente à penicilina.

Cerca de $64,4 \%$ dos isolados foram resistentes a cefalotina, sendo este antibiótico uma cefalosporina de primeira geração. Também foi possível detectar $79,7 \%$ de resistência a cefoxitina, e $84,7 \%$ dos isolados foram resistentes a oxacilina.

A resistência a ceftriaxona foi detectada em $62,7 \%$ dos isolados. A resistência à ciprofloxacina e clindamicina foram detectadas em $57,6 \%$ e $74,6 \%$ dos isolados resistentes, respectivamente. Também foi possível observar a resistência à enrofloxacina, gentamicina e imipenem em $18,6 \%, 15,3 \%$ e $16,9 \%$ dos isolados, respectivamente.
Em relação á linezolida, 59,3\% dos isolados foram resistentes. Foram detectados 40,7\% de resistência a norfloxacina e $52,5 \%$ a tetracicilina.

O desenvolvimento da resistência aos antimicrobianos por diversos patógenos vem aumentando a cada dia, o que torna de grande importância a pesquisa de novos agentes para combater as infecções ${ }^{9}$, A maioria das bactérias tem grande capacidade de se adaptar aos antibióticos, tornando-se mais resistentes e dificultando o tratamento das infecções, pois, os mecanismos de resistência bacteriana são complexos e variados ${ }^{17}$.

Dos 59 isolados de Staphylococcus spp. avaliados, foram detectadas 10 amostras com bordas definidas, sendo estes classificados como â-lactamase negativa; 18 isolados apresentaram halo difuso, sendo classificados como â- lactamase positiva; e 31 isolados foram resistentes á penicilina, conforme o gráfico a seguir.

No presente estudo foi possível fazer o fenótipo MLS $_{B}$ de 37 isolados, onde 11 isolados apresentaram resistência induzida da clindamicina, 17 isolados foram resistentes aos dois antimicrobianos, tanto clindamicina quanto a eritromicina e 3 isolados foram sensíveis tanto ao disco de antibiótico da clindamicina, quanto ao da eritromicina (Figura 2). Também foi possível verificar que 5 isolados apresentaram resistência intermediária para eritromicina, e apenas 1 foi intermediário tanto para clindamicina quanto para eritromicina (Tabela 4).

Dos isolados avaliados quanto à produção de hemolisinas, 50,9\% foram hemolíticos. Destes, $35,6 \%$ apresentou hemólise total, denominada como â-hemolisina e 15,3\% a hemólise parcial, chamada de á-hemolisina (Tabela 6).

O SHA foi positivo em 59,3\% (35/59) dos isolados sendo que destes, 13 não apresentaram hemolisinas (Figura 4).

\begin{tabular}{|c|c|c|c|}
\hline \multicolumn{3}{|c|}{$\begin{array}{c}\text { Tabela 2 Distribuição dos Staphylococcus spp. Provenientes de } \\
\text { Amostras em seus Respectivos Setores }\end{array}$} \\
\hline Amostras & S. aureus & $\begin{array}{c}\text { S.epidermidi } \\
\text { S.saprophytic } \\
\text { us }\end{array}$ \\
\hline Jalecos enfermaria & 2 & 3 & 8 \\
\hline Jalecos UTI & 0 & 4 & 0 \\
\hline $\begin{array}{c}\text { Estetoscópios } \\
\text { enfermaria }\end{array}$ & 1 & 11 & 4 \\
\hline Estetoscópios UTI & 2 & 9 & 0 \\
\hline Maçanetas enfermaria & 1 & 4 & 6 \\
\hline Macanetas UTI & 0 & 3 & 1 \\
\hline Total & $\mathbf{6}$ & $\mathbf{3 4}$ & $\mathbf{1 9}$ \\
\hline
\end{tabular}




\begin{tabular}{|c|c|c|c|c|}
\hline Antibiótico & Sigla & $\begin{array}{c}\text { Resistent } \\
\text { e }\end{array}$ & $\begin{array}{c}\text { Intermediári } \\
\text { o }\end{array}$ & Sensível \\
\hline Cefalotina 30uq & CFL & 38 & 2 & 19 \\
\hline Cefoxitina $30 \mathrm{uq}$ & CFO & 47 & 0 & 12 \\
\hline Ceftriaxona $30 \mu q$ & CRO & 25 & 20 & 14 \\
\hline Ciprofloxacina 30uq & CIP & 37 & 3 & 19 \\
\hline Clindamicina 2uq & CLI & 44 & 8 & 7 \\
\hline Enrofloxacina 10uq & ENO & 11 & 6 & 42 \\
\hline Gentamicina $10 \mu \mathrm{g}$ & GEN & 9 & 3 & 47 \\
\hline Imepenem 10ug & IMP & 10 & 1 & 48 \\
\hline Linezolida $30 \mu \mathrm{g}$ & LNZ & 35 & 0 & 24 \\
\hline Norfloxacina $10 \mu \mathrm{g}$ & NOR & 24 & 9 & 26 \\
\hline Oxacilina $1 \mu \mathrm{g}$ & OXA & 50 & 0 & 9 \\
\hline Penicilina $10 \mu \mathrm{g}$ & PEN & 57 & 0 & 2 \\
\hline Tetraciclina $10 \mu \mathrm{g}$ & TET & 31 & 8 & 20 \\
\hline
\end{tabular}

\begin{tabular}{|c|c|c|c|c|c|c|c|c|c|}
\hline & \multicolumn{10}{c|}{ Tabela 4. Fenótipo MLS $_{\mathrm{B} .}$} \\
\hline Antibióticos & S. aureus & \multicolumn{2}{c|}{ S. epidermidis } & \multicolumn{3}{c|}{ S. saprophyticus } \\
\hline & $\mathrm{R}$ & $\mathrm{I}$ & $\mathrm{S}$ & $\mathrm{R}$ & $\mathrm{I}$ & $\mathrm{S}$ & $\mathrm{R}$ & $\mathrm{I}$ & $\mathrm{S}$ \\
\hline Clindamicina & 4 & - & - & 8 & - & - & - & - & - \\
\hline Eritromicina & - & - & - & & 3 & - & - & 2 & - \\
\hline Clindamicina/Eritromicina & 3 & 1 & 1 & 10 & - & 1 & 4 & - & 1 \\
\hline
\end{tabular}

\begin{tabular}{|c|c|c|c|c|}
\hline \multicolumn{5}{|c|}{ Tabela 5. Níveis de produção de "slime" relacionada com cada } \\
espécie de Staphylococcus spp. \\
Espécie & Ausente & Fraco & Moderado & Forte \\
\hline S. aureus & 2 & 1 & 3 & 0 \\
\hline S. epidermidis & 10 & 5 & 17 & 3 \\
\hline S. saprophyticus & 2 & 10 & 6 & 0 \\
\hline Total & 14 & 16 & 26 & 3 \\
\hline
\end{tabular}

\begin{tabular}{|c|c|c|}
\hline Espécie & Total & Parcial \\
\hline S. aureus & 6 & 0 \\
\hline S. epidermidis & 12 & 9 \\
\hline S. saprophyticus & 3 & 0 \\
\hline Total & 21 & 9 \\
\hline
\end{tabular}




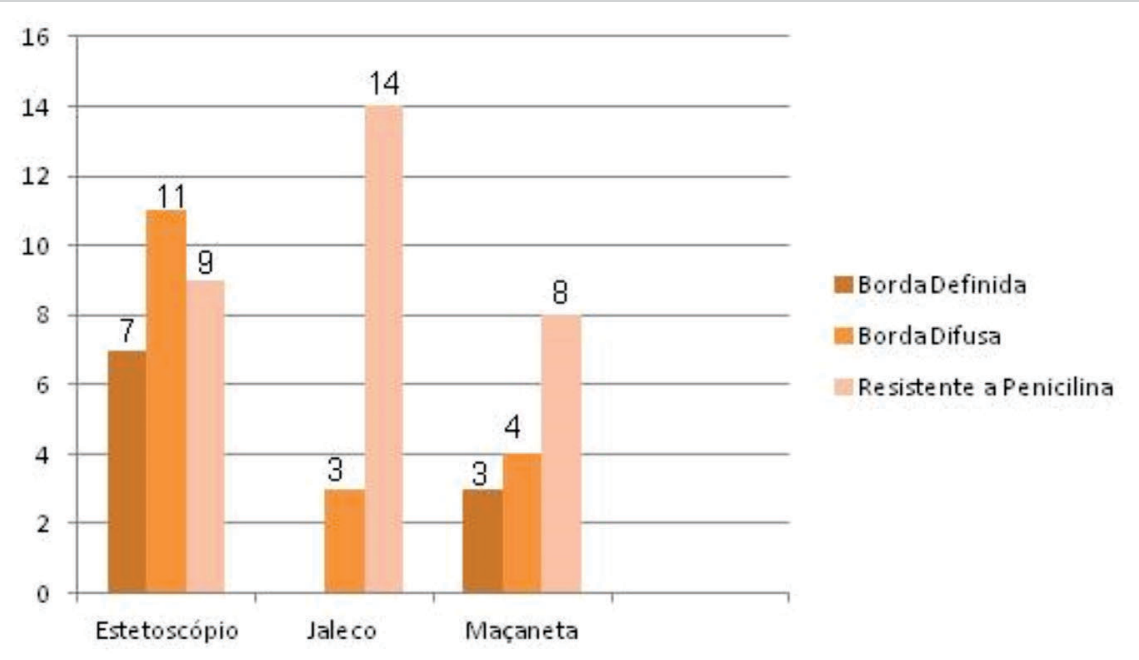

Figura1. Quantidade de micro-organismos isolados com a característica da produçã de â-lactamase e resistência à penicilina nos isolados de Staphylococcus de acordo com o sítio.

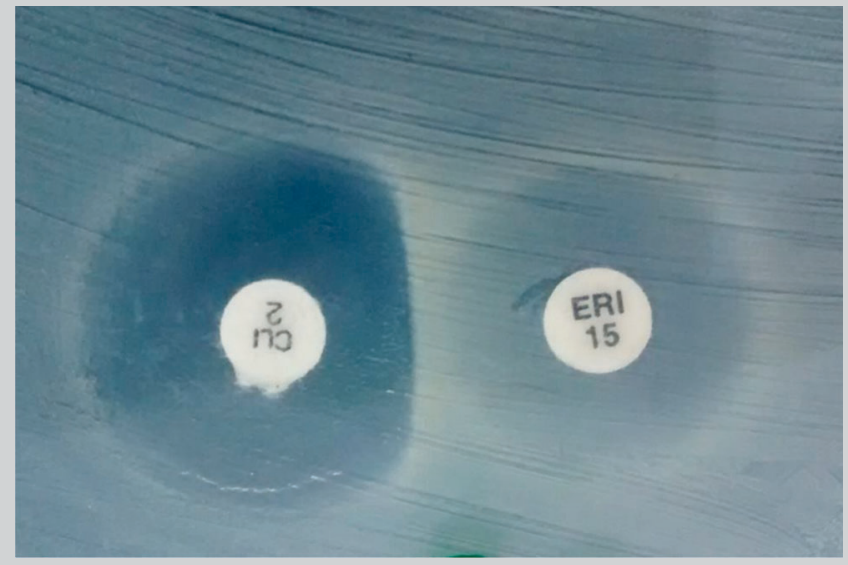

Figura 2. Fenótipo $M_{L} S_{B}$ indutivo do $S$. epidermidis.

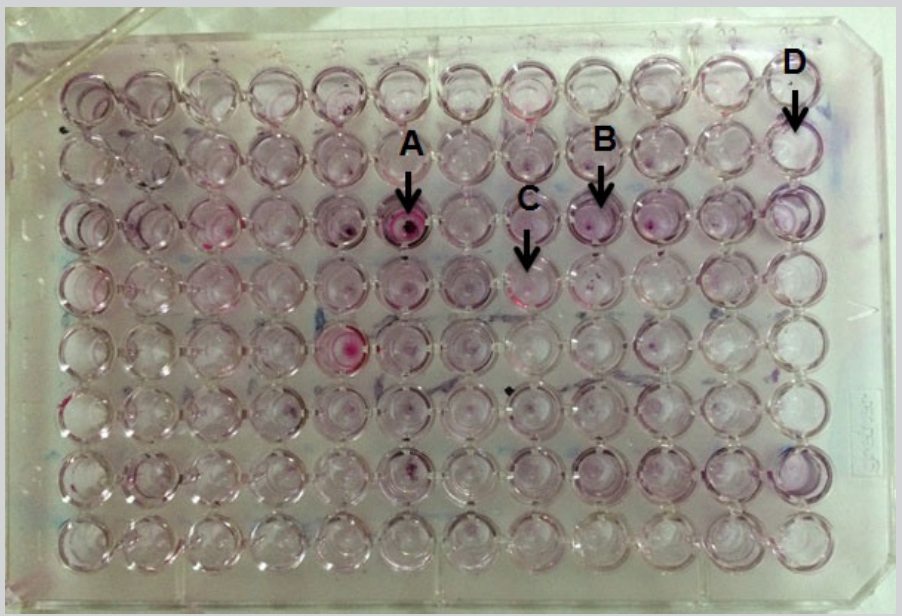

Figura 3. Produção de "slime", em Staphylococcus spp. A- forte produtor $(+++)$, B- moderado produtor $(++)$, C- fraco produtor (+), D- não produtor (-) 


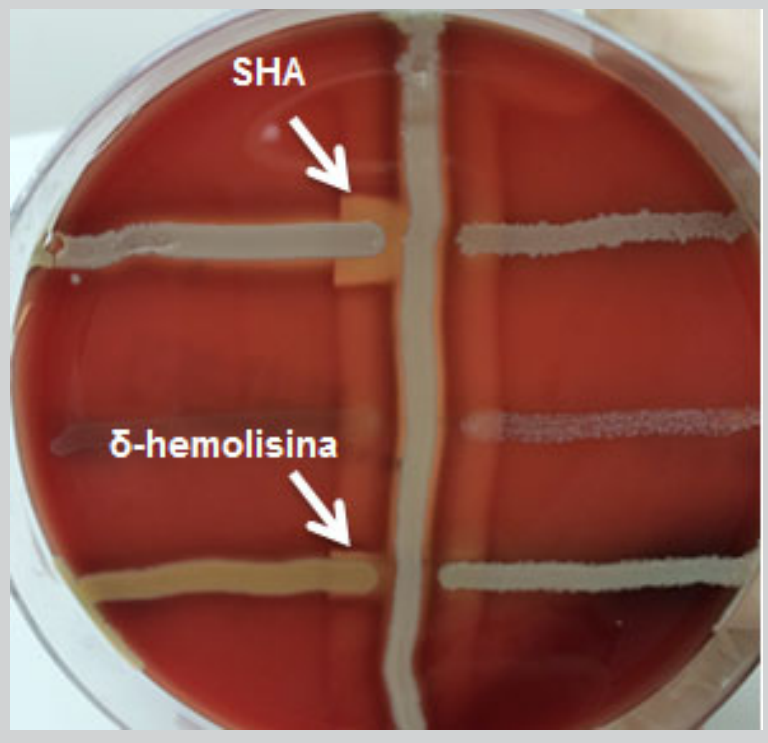

Figura 4: SHA positivo de S. Saprophyticus e ähemolisina de $S$. epidermidis.

\section{DISCUSSÃO}

O crescimento de Staphylococcus spp. no total de amostras foi significativo, com isso, compreende-se que esse micro-organismo tem grande potencial de ser disseminado pela equipe médica durante o atendimento à paciente. Embora seja difícil a associação da transmissão de microorganismos das superfícies para pacientes e consequentemente a aquisição de infecções relacionadas à assistência à saúde. Estudos têm comprovado que tais superfícies podem hospedar micro-organismos resistentes, tornando um potencial reservatório ${ }^{18}$.

As infecções causadas por $S$. aureus são responsáveis por altas taxas de morbidade e mortalidade, porém, o S.epidermidis é o agente infeccioso mais comumente isolado em UTIs. Por estar presente na pele de pessoas saudáveis, é responsável por causar grandes infecções oportunistas já que pode ser transmitido pelos profissionais de saúde durante e após procedimentos de rotina ou invasivos. Neste trabalho o crescimento de $S$. epidermidis foi mais frequente que as demais cepas $^{19}$.
A resistência dos Staphylococcus spp. à penicilina é um fenômeno mundial e com prevalência crescente, apesar dos esforços para conter o aumento da disseminação de isolados resistentes ${ }^{20}$. O crescente número de cepas resistentes à penicilina já é esperado, devido ao fato desse antibiótico ser amplamente difundido no tratamento de infecções ${ }^{21}$. No presente trabalho cerca de $96,6 \%$ foram resistente à penicilina, confirmando o que outros autores afirmam sobre a resistência da penicilina.

A clindamicina costuma ser escolhida como tratamento inicial ou definitivo para infecções de pele e partes moles adquiridas na comunidade. Apresenta atividade antimicrobiana mesmo tendo uma elevada carga bacteriana no local da infecção ${ }^{17}$, porém, no presente trabalho observa-se uma quantidade significante de cepas resistente a esse antibiótico, cerca de $79,7 \%$ foram resistentes.

$O$ uso do linezolida é proibido em alguns países por ser considerado um medicamento extremamente tóxico, de custo elevado e é indicado para o tratamento da pneumonia nosocomial por $M_{R S A}{ }^{22}$. A eficácia desse antibiótico é semelhante à vancomicina e a resistência é rara ${ }^{2}$. Neste trabalho 
o número de cepas resistentes também foi relativamente alto, cerca de $59,3 \%$.

A produção de enzimas â-lactamases tem sido relatada como um importante mecanismo de resistência a antibióticos â-lactâmicos, hidrolisando o anel beta-lactâmico pela quebra da ligação amida, perdendo assim, a capacidade de inibir a síntese da parede celular bacteriana ${ }^{23}$.

A produção de â-lactamase foi detectada a partir da borda do halo de inibição do disco de antibiótico da penicilina. As bordas dos halos de inibição que ficaram bem definidas foram consideradas â-lactamase negativa e as bordas difusas como â-lactamse positiva. Das cepas que já foram resistentes a penicilina, as que não foram resistentes 18 de 28 foram consideradas âlactamase positiva.

O fenótipo $M_{L S} S_{B}$ é um mecanismo de resistência bacteriana. Para a detecção do fenótipo $\mathrm{MLS}_{\mathrm{B}}$ os isolados foram submetidos ao teste de duplo disco (eritromicina e clindamicina) para caracterização dos fenótipos de resistência a macrolídeos. A clindamicina é usada no tratamento de infecções de pele e tecidos moles, causadas por espécies de estafilococos, além de ser uma alternativa para pacientes alérgicos a penicilina ${ }^{24}$.

A eritromicina presente no disco difunde-se pelo meio de cultura e induz a resistência à clindamicina, resultando em um achatamento do halo de inibição, adjacente ao disco de eritromicina, com a forma da letra $D$ (efeito $D$ ) ${ }^{14}$. Quando ocorre esse achatamento, pode haver falha terapêutica caso esse medicamento seja utilizado.

O total de $76,3 \%$ dos isolados foram positivos para produção de "slime", e o principal produtor isolado foi de $S$. epidermidis. Alguns autores consideram que até $60 \%$ das infecções hospitalares estão associadas à formação de biofilme por micro- organismos oportunistas e pela utilização de dispositivos médicos ou implantes cirúrgicos, e o $S$. epidermidis é o agente infeccioso mais encontrado, frequentemente, nesses dispositivos ${ }^{25,26}$.

Na literatura, dados envolvendo a produção de hemolisina e/ou sinergismo hemolítico por Staphylococcus spp. com amostras humanas ainda são muito escassos.

O presente estudo detectou 21 isolados formadores de hemolisina total, representada pela â-hemolisina, uma enzima que apresenta atividade de esfingomielinase, sendo tóxica para varias células, como hemácias, macrófagos e leucócitos. Sua ação consiste catalisar a hidrólise dos fosfolipídios da membrana celular com lise proporcional à concentração de esfingomielina exposta na superfície celular das células suscetíveis ${ }^{27}$.

A literatura relata que isolados não hemolíticos com produção de sinergismo podem ser portadores da ä-hemolisina, a qual é expressa somente na presença da â-hemolisina. Além disso, acredita-se que o fenômeno de sinergismo hemolítico seja independente da produção de hemolisinas, porém sua ação é considerada potencia-lizadora para isolados que são hemolíticos ${ }^{28}$.

\section{CONCLUSÃO}

A presença de Staphylococcus foi frequente em fômites hospitalares. Desta forma, a disseminação deste agente como patógeno hospitalar é preocupante, uma vez que pode aumentar o tempo de internação e tratamento dos pacientes. Associado a isso, a utilização de estetoscópios sem as devidas formas de prevenção de contaminação pode disseminar as infecções bacterianas. 


\section{REFERÊNCIAS}

1. Brasil. Ministério da Saúde. Portaria $n^{\circ} 2616$ de 13 de maio de 1998. Regulamenta as ações de controle de infecção hospitalar no país. Diário Oficial da República Federativa do Brasil.1998 mai. 15; 15 maio 1998.

2. Arantes T, Paixão GOD, Silva MD, Castro CSA. Avaliação da colonização e perfil de resistência de Staphylococcus aureus em amostras de secreção nasal de profissionais de enfermagem. Rev Bras Farm; 2013, 94(1): 30-34

3. Tanaka, Viggiani AMFS, Person OC. Bactérias veiculadas por formigas em ambiente hospitalar. Arquivos médicos do ABC; 2007, 32(2): 60-63.

4. Allegtanzi B, Nejad SB, Combescure C. Burden of endemic health-care-associated infection in developing countries; Systematic review and meta-analysis. The Lancet; 2011, 377(9761): 228-241.

5. Andrade D, Leopoldo VC, Haas VJ. Ocorrência de bactérias multirresistentes em um centro de terapia intensiva de Hospital Brasileiro de Emergências. Rev Bras Ter Intensiva; 2006, 18(1): 27-33.

6. Oliveira AC, Damasceno QS, Piscoya M, Nicoli JR. Epidemiologic characteristics of resistant microorganisms present in reserves from an intensive care unit. Am J Infect Control; 2011, 40(2):186-7

7. Cavalcanti SMM, França ER, Viela MA, Montenegro F, Cabral C, Medeiros ACR. Estudo comparativo da prevalência de $S$. aureus importado para as unidades de terapia intensiva de hospital universitário, Pernambuco, Brasil. Bras J Infect Dis; 2006, 9(4): 436446.

8. Basset M, Nicco E, Mikulska M. Why is communityassociated MRSA spreading across the world and howwill it change clinical practice. Int J Antimicrob Agents; 2009, 34(1): 15-9.

9. Catão RMR, Belém LF, Silva PMF, Nunes LE, Fernandes AFC. Avaliação da colonização nasal por Staphylococcus aureus em funcionários de um serviço de saúde em Campina Grande-PB. Revista Bio Far; 2012, 7(1): 19834209.

10. Ratti RP, Sousa CP. Staphylococcus aureus meticilina resistente (MRSA) e infecções nosocomiais. Rev Ciên Farm Básica APL; 2009, 30(2): 1-89.

11. Koneman E, Jr WW, Allen S, Procop G, Schireckenberger P, Woods G. Diagnóstico microbiológico: texto e atlas colorido. $6^{a}$ edição. Rio de Janeiro: Guanabara Koogan, 2008.

12. Clinical and Laboratory Standards Institute.Performance standards for antimicrobial disk susceptibility tests. Approved standards. CLSI document M1-A3. Clinical and Laboratory Standards Institute; Wayne, Pa; 2013.

13. Kohner JP. Comparison of susceptibility testing methods with mecA Gene analysis for determining oxacilin (methicilin) resistance in clinical isolates of Staphylococcus aureus and coagulase -ative staphylococcus spp. J Clin Microbiol; 1998, 37(9): 29522961.
14. Clinical and Laboratory Standards InstitutePerformance standards for antimicrobial disk susceptibility tests. Approved standards. CLSI document M2-A3. Clinical and Laboratory Standards Institute. Wayne, Pa; 2011.

15. Christensen GD, Simpson WA, Younger JJ, Baddour LM, Barrett FF, Melton DM, et al. Adherence of coagulasenegative Staphylococci to plastic tissue culture plates: a quantitative model for the adherence of Staphylococcus to medical devices. J Clin Microbiol; 1985, 22(6): 9961006.

16. Demo, M. Caracterizacion $Y$ studios de patogenicidad de cepas dela genero Staphylococcus asiladas de leches mastiticas. Instituto de Microbiologia, Universidad Nacional de Rio Cuarto, 1996.

17. Perlroth J, Kuo M, TanJ. Adjunctive use of rifampin for the treatment of Staphylococcus aureus infections: a systematic review of the literature. Arch Intern Med; 2008 168(8): 805-19.

18. Ferreira AM, Barcelos LS, Rigotti MA, Andrade D, Andreotti JT, Almeida MG. Superfícies do ambiente hospitalar: um possível reservatório de micro-organismos subestimado? Revisão integrativa. Rev enferm UFPE on line. 2013, 7(esp): 4171-82

19. Abbeg PTGM, Silva LL. Controle de infecção hospitalar em unidade de terapia intensiva: estudo retrospectivo Hospital. Semina: Ciên Biológic da Saúde; 2011, 32(1): 47-58.

20. Faria NA, Oliveira DC, Westh $H$, Monnet DL, Larsen AR, Skov $R$, et al. Epidemiology of emerging methicillin-resistant $S$. aureus (MRSA) in Denmark: a nationwide study in a country with low ptevalence of MRSA infection. J Clin Microbiol; 2005, 43(4): 1836-1842.

21. Martins SCS, Martins CM, Albuquerque LMB, Fonteles TV, Rego SL, Junior GSF. Perfil de Resistência de cepas de Staphylococcus coagulase positive isoladas de manipuladores de alimento. B. CEPPA; 2009, 27(1): 4352.

22. Weigelt J, Itani K, Stevens D. Linezolid versus vancomycin in treatment of complicated skin and soft tissue infections. Antimicrob Agents Chemother; 2005, 49(6): 2260-6.

23. Williams JD. â-lactamases and â-lactamase inhibitors. Inter. J. Antimicrob. Agents;1999, 12(1): 3-7.

24. Fiebelkorn KR, Crawford SA, Mceimeel ML, Jorgensen $\mathrm{JH}$. Practic AL, disk diffusion method for detection of inducible clindamycin resistance in Staphylococcus aureus and coagulase-negative staphylococci. J Clin Microbiol; 2005, 41(10): 4740-4.

25. Batista TF, Rodrigues MCS. Vigilância de infecção de sítio cirúrgico pós-alta hospitalar em hospital de ensino do Distrito Federal, Brasil: estudo descritivo retrospectivo no período 2005-2010. Epidemiol Serv Saúde; 2012 21(12): 253-264. 
26. Padoveze MC. Biofilme: o inimigo invisível, Parte I. 2015 Núcleo de Acessoria, Capacitação e Especialização. Disponível em: <http://nascecme.com.br/biofilme-oinimigo-invisivel/>. Acesso em: 18 out. 2015.

27. Henrique M. Staphylococcus spp. 2015. Farmácia: minha vida. Disponível em: <http:// farmaciaminhavida.blogspot.com.br/2014/07/ staphylococcus-spp.html> Acesso em:19 out. 2015.

28. Coelho SMO, Reinoso E, Pereira IA, Soares LC, Demo M, Bogni $C$, et al. Virulence factors and antimicrobial resistence of $S$. aureus isolated from bovine mastitis in Rio de Janeiro. Pesq Vet Bras; 2009, (29): 369-374.

\section{Correspondência}

Lidiane de Castro Soares

Universidade Severino Sombra. Rua Paulo Pinheiro Guedes, 48 - Cosmos

Rio de Janeiro - Rio de Janiero - Brasil

Cep: 23061-540

E-mail: biolidi@yahoo.com.br 